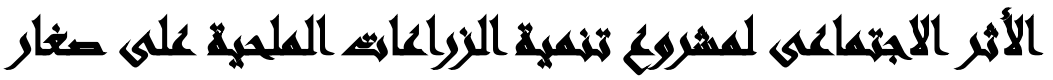

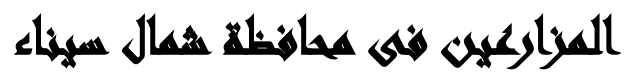

[०]

حاتم أحمد عبد المنعم(')- هثام إبراهيم القصاص(')- عاشورة حسين مرسى(؟)

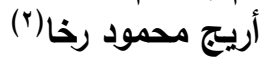

() معهد الدراسات والبحوث البيئية، جامعة عين شمس r ؟) مركز بحوث الصحراء

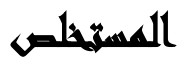

تهدف الدراسة الحالية الى التعرف على الأثر الإجتماعى لمشروع تتمية الزراعات

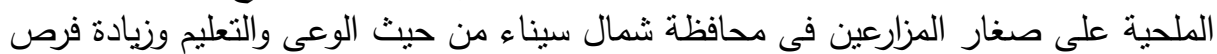

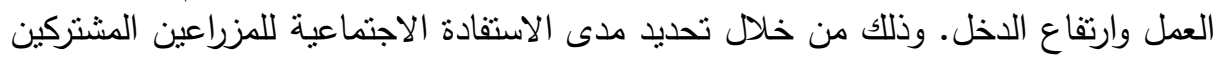

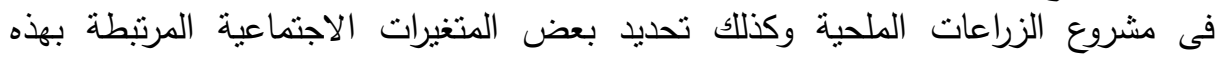

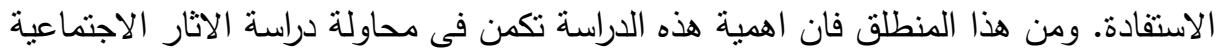

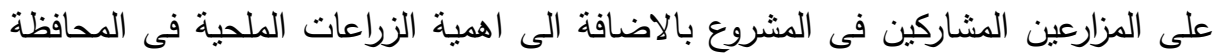

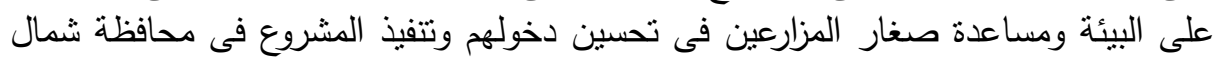
سيناء يضاعف من اهمية الدراسة بسبب اهمية سيناء للادمن القومى. تعد الدراسة الوصفية التحليلية بإستخدام منهج المستح الاجتماعي بالعينة. ونئة ونم اختيار

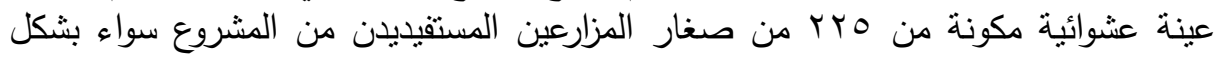

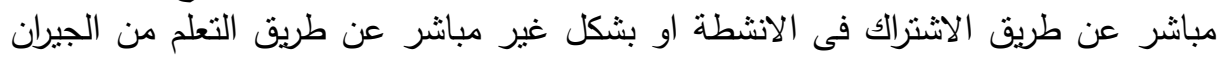

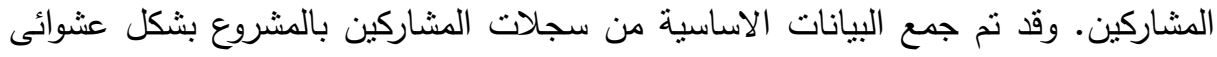

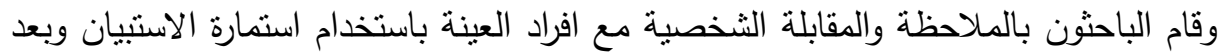

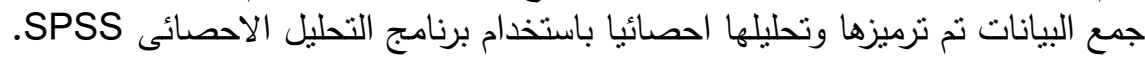

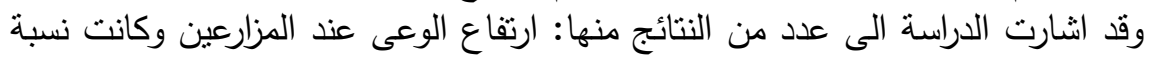

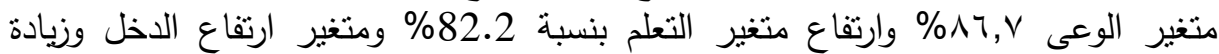

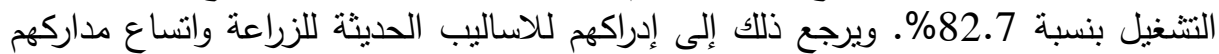

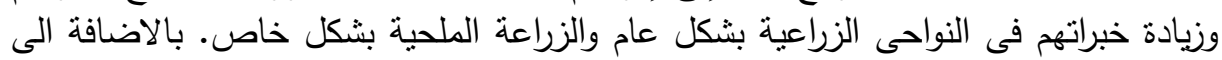

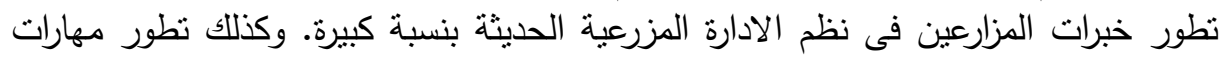
المرأه فى تصنيع المنتجات الزراعية.
\end{abstract}


وقد اوصى البحث بانثاء جمعية تعاونية زراعية تضم صغار المزارعين، وزيادة عدد الزئ المشروعات التتموية الزراعية وخاصة التى تعتمد على الزراعات الملحية. مساعدة المزارية المعارعين فى عمليات التسويق للمنتجات المصنعة، وتطوير عمليات الرىى.

\section{Xanill}

تم تعريف التتمية علي أساس الجهود المبذولة لتخفيف حدة الفقر وتحقيق العدالة وتوفير فرص العمل في ظل اقتصاد نام، وقد ساند البنك الدولي هذا الاتجاه التتموي. وأعلن أن World ) التحدي أمام التتمية هو تحسين نوعية الحياة خاصة في دول العالم الفقيرة

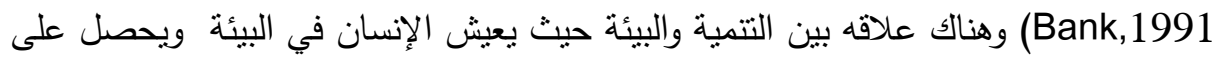
مقومات حياته من مختلف مكوناتها وأنظمتها ومواردها وتعتبر تلبية الاحتياجات الأساسية للإنسان وتحسين ظروف حياته وتحقيق طموحاته من الأهداف الرئيسية للتتمية من خلال مختلف الأنشطة التي يمارسها على البيئة ومحيطها الحيوي وهي أنشطه يكون فيها الإنسان

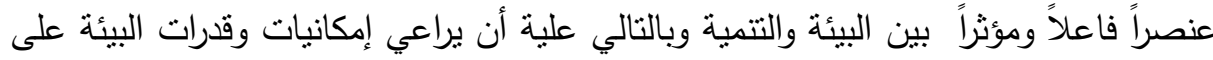

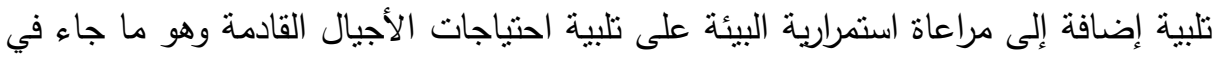
مفهوم التتمية المستديمة وهنا تبرز العلاقة بين البيئة والتتمية وهي علاقات توافق وليس اليس الئه

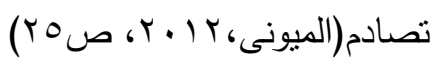

وتسعى الحكومة المصرية لحل المشاكل التى نواجه خطط التتمية عن طريق وضع

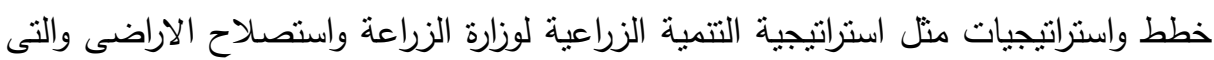
تهدف للتمية الزراعية المستدامة حتى عام .ب.r.r، وعلى رأسها تحسين مستوى معيشة السكان المحليين وتخفيض معدلات الفقر والاستخدام المستدام للموارد الزراعبة الطبيعية وتتمية الموارد البشرية وخلق فرص عمل للثباب. وتبلغ مساهمة القطاع الزراعي في الناتج المحلي

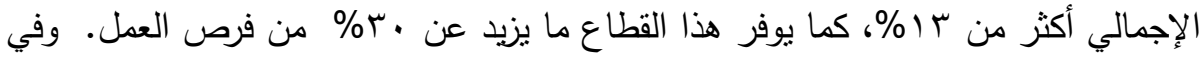
نفس الوقت، نجد أن نحو \%ov من إجمالي السكان في مصر يعيشون في المناطق الغير

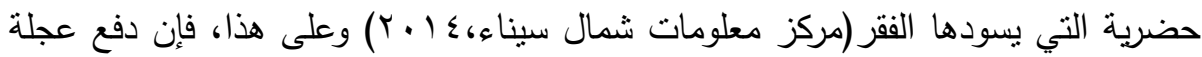
التتمية الزراعية والريفية المستدامة قُُماً- كوسيلة للحد من الفقر وتحقيق الأمن الغذائي في 
ظل التغيرات المناخية المتوقعة - يعدّ شرطاً أساسياً لتحقيق التتمية المستدامة (حندوسة،

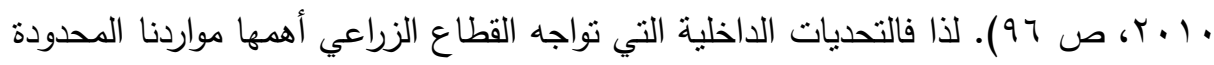

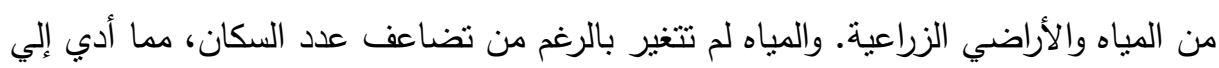

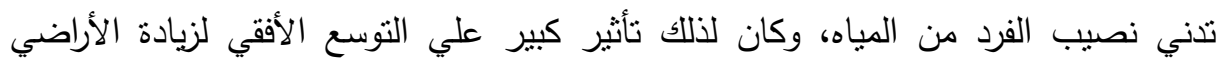

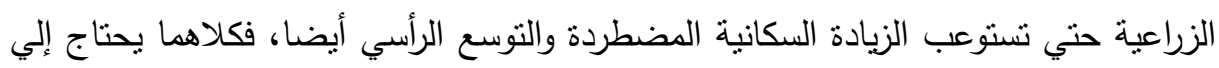

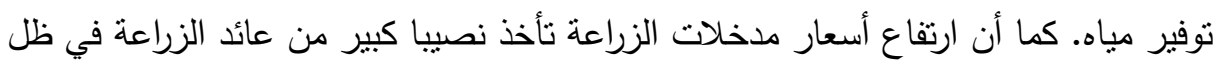

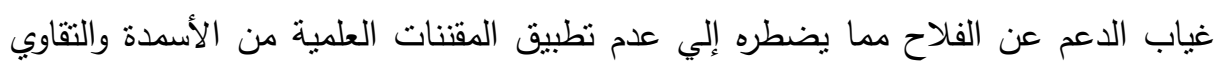
والتي تجعله يستقيد من نتائج البحوث الزراعية. وهذه الأمور تتطلب تدخل العلماء لمواجهة

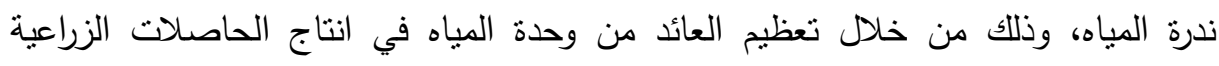

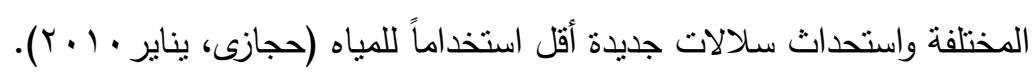
وما لا شك فيه أن التخطيط الجيد يحقق التنمية المتكاملة والتي تعني مجموعة البرامج

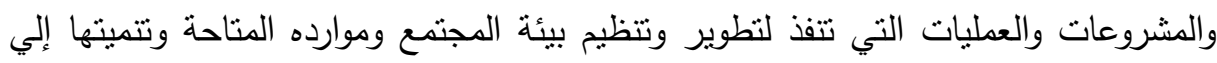
أقصي حد ممكن بالاعتماد علي الجهود الحكومية والأهلية المتتاسقه والمشاريع التتموية مهما

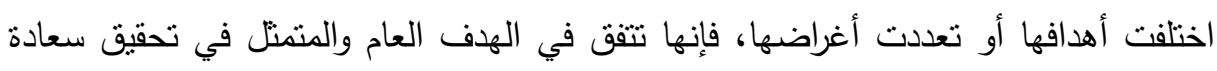

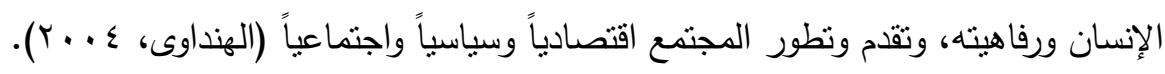
فى سبيل تحقيق هذه التتمية لابد من وجود تقييم كامل للمشروعات ومن اهمها التقييم

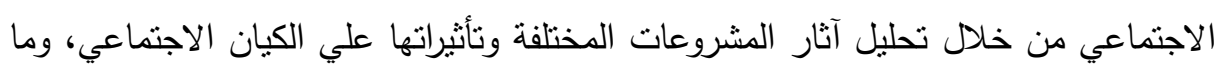
تخلفه تلك المشروعات من مشكلات او جدوى اجنماعية، للإستفادة في تحسين أداء

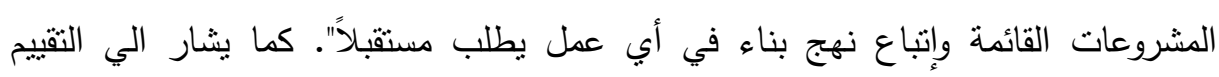

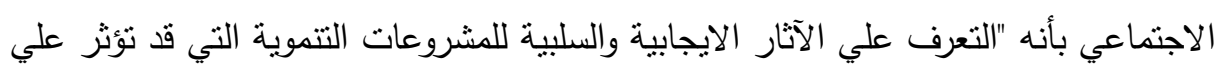

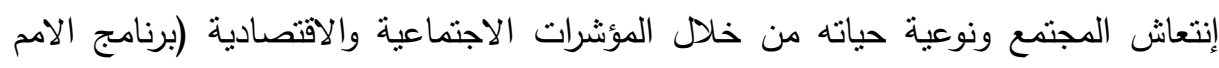

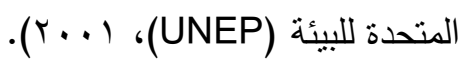




\section{And}

تعتبر منطقة شمال سيناء من المناطق الزراعية الواعدة ولكن تواجهها العديد من التحديات ومنها الإجهادات المتمثلة فى الجفاف وارتفاع مستوى الملوحة في المباه والتربة، وانخفاض خصوبة التربة مع إرتفاع معدلات الإثعاع الثمسى مما يعمل على رفع درجة الحرارة (El-Shaer \& El-Morsy,2008). بالإضافة إلى ضعف خبع خبرة المزارعين الوافدين إلى تلك المنطقة من المحافظات الاخرى والبدو فى التعامل مع تلك الإجهادات لإتباعهم الإنه أساليب الزراعة التقليدية (El-Shaer \& El-Morsy,2008). لذا أصبح من الضرورى

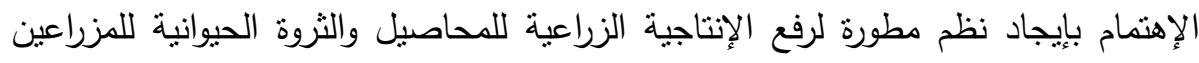

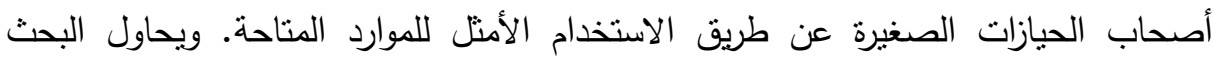

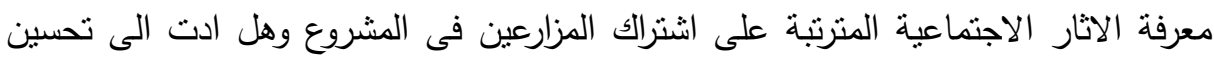
حالتهم الاجتماعية من حيث الوعى والتعليم والدخل وتوفير فرص الادئ عمل.

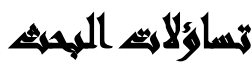

- ما هي الآثار الاجتماعبة لمشروع الزراعات الملحية علي مجتمع الدراسة؟

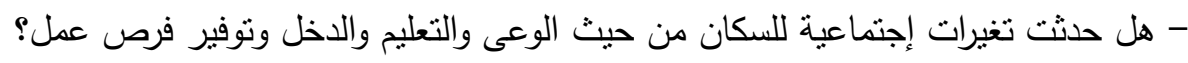
إن الإجابة علي هذه التساؤلات سوف تساهم في دراسة الآتار الاجتماعية لأنشطة المشروع.

\section{أهساهن المبهش}

يستهدف هذا البحث دراسة الأثر الإجتماعى لمشروع الزراعات الملحية على المزارعين أصحاب الحيازات الصغيرة بشمال سيناء وذلك من خلال تحقيق الاهداف الفرعية التالية: 1-تحديد مدى الاستفادة الاجتماعية للمزراعين المشتركين فى مشروع الزراعات الملحية.

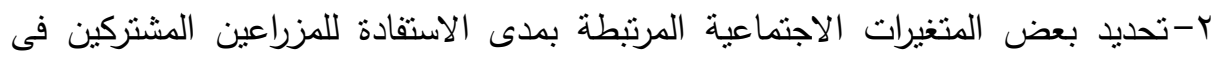
مشروع الزراعات الملحية. 


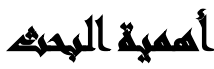

النقاط التالية لها آثار هامة على العوامل الاجتماعية والاقتصادية ومنها نوفير فرص العمل المحلي التي تؤثر تأثيراً مباشرا على أصحاب المصلحة وهم صغار المزارعين: 1-نساعد عملية تقييم الاثر الاجتماعى للمشروعات على تحديد نقاط الضعف وكيفية مواجنتها وتحديد الظروف والاسباب النى ساعدت على تحقيق اهداف المشروع او العكس الهن وتحديد بعض المقترحات التى تساعد على إنجاح المشروع.

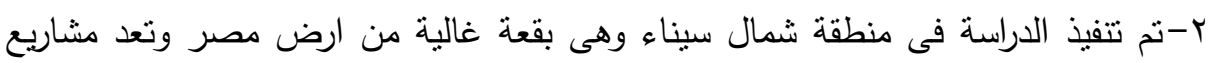
التتمية بها حماية للامن القومى المصرى بالاضافة الى تحسين معيشة ابناء المنطقة. r-تعد المشروعات الزراعية ذات اهية اقتصادية وتتموية لسكان المناطق الصحراوية بوجه عام ولسكان المناطق الحدودية بوجه خاص. צ-ركزت الدراسة على محدودى الدخل (صغار المزاعين) من خلال دعمهم ومحاولة رفع

مستوى معيشتهم، وذلك ما حرصت عليه استراتيجية التتمية الزراعية المصرية ـ. •.r. ه-ثقع الدراسة فى منطقة صحراوية محدودة الموارد الطبيعية (ندرة المياه وملوحة التربة والمياه). ومن هذا المنطلق تبرز اهمية الزراعات الملحية التى تعتمد على زراعة المحاصيل المتحملة للملوحة عن طريق استخدام الموارد الهامثية متل التربة والمياه الجوفية المالحة مما يمكن أن يساهم في تحقيق التتمية الاجتماعية والاقتصادية وحل مشاكل نقص الغذاء للإنسان والحيوان.

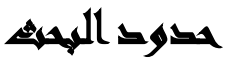

المجال الزمني: تم إجراء البحث الميداني خلال شهرى ابريل ومايو عام 7 ــr. المجال الجغرافي: فى محافظة شمال سيناء النى تقع في الثمال الثرقي بجمهورية مصر

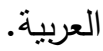




\section{المخاهيه}

1 - مفهوم التنمية: وقد وضعت الامم المتحدة خلال عام 1900 تعريف للتنمية وهو ان "تتمية المجتمع المحلي هي عملية مصممة لخلق ظروف التقدم الاقتصادي والاجتماعي في المجتمع عن طريق مشاركة الأهالي ايجابياً في هذه العملية والإعتماد الكامل علي في فئي مبادأة الأهالي بقدر المسنطاع". والتعريف الخاص بمنظور البرنامج القومي للتتمية الريفية

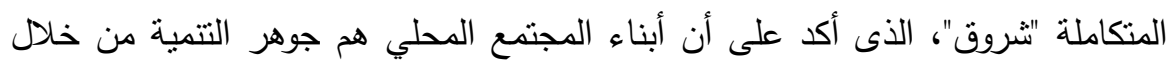
مبادراتهم وإسهاماتهم ومشاركتهم الإيجابية والفعالة في البرنامج فكراً وتخطيطاً. (ريحان،

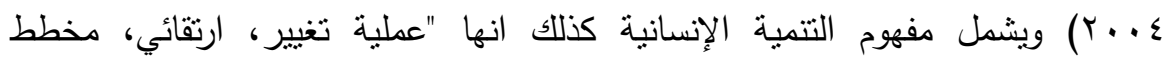
للنهوض الثنامل بجودة حياة الناس، في مختلف جوانبها، يشارك فيها الناس بعدالة لتحمل التبله

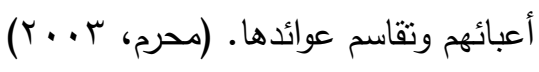

ץ - مفهوم تقييم الاثر الاجتماعى للمشروعات: يعرف التقييم الاجتماعي انه عملية تقدير النتائج الاجتماعية المترتبة على اقامة مشروع معين خلال فترة معينة مع تحديد النتائج الايجابية والسلبية بشكل كمى كلما امكن. ويشمل التقييم الاجتماعى كل المتغيرات الثقافية والسكانية بحيث يتضمن العادات والتقاليد والمعتقدات والاخلاق العامة والقيم (Burdge, 1999). ويقصد بها فى هذه الدراسة مجموعة التغيرات الاجنماعية التى ولى والتهن

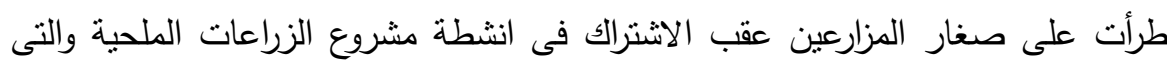
استخدم فى قياسها مجموعة من المؤشرات وهى دور المرأه ومدى مساهمتها فى الاعمال الزراعية والتخلص من البطالة ومدى التغير فى درجة الوعى وفى تعلم الاساليب المتطورة

$$
\text { فى الزراعة. }
$$

ب- مفهـوم الزراعـات الملحيـةة: هـى الممارسـات الزراعيـة المتطـورة التى تسـتخدم

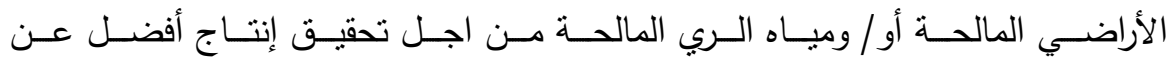

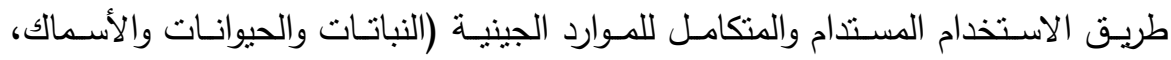

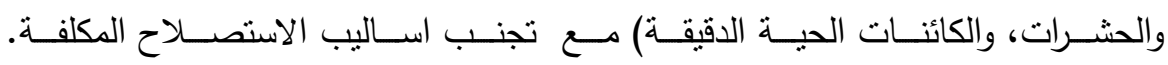


المياه المالحة التي يتم استخدامها في الري يمكن أن تكون مياه البحر او الميـاه قليلة

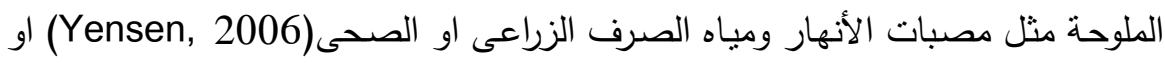
حتى المياه المهدرة من تربية الاحياء المائية(Porto et al, 2006).

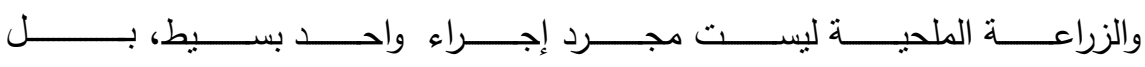

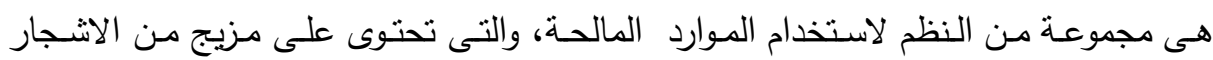

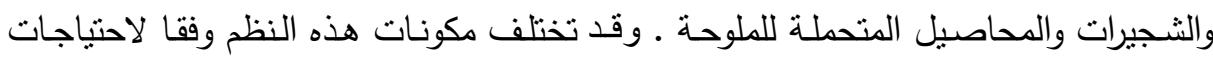

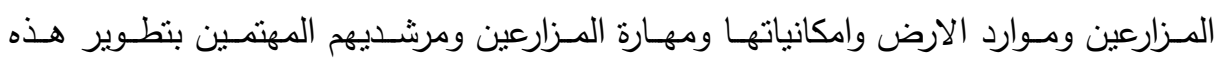
النظم(Qureshi, et al, 1998). צ - صغار المزارعين: هى فئة صغار المنتفعين من المزارعين وشباب الخريجين ومستأجري الاراضي بواقع عشرة فدادين فأقل.

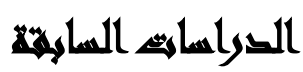

دراسة (نصار، ج . . Y) إستهدفت التعرف علي الوضع الراهن للخصائص الإجتماعية

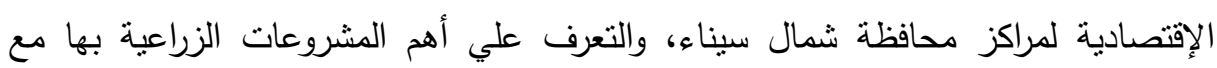

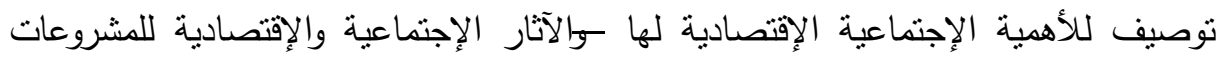
الزراعية، ووضع تصور نحو إستراتيجية لتتمية مراكز محافظة شمال سيناء زراعياً. اتضح من النتائج ان هناك أثنار للتغيرات الدخل والمستوى التتموى مع الانفاق الثهرى. وإختلاف المستويات التتموية بين المراكز حيث يقل الإنفاق الإستهلاكى بإنفاض المستوى

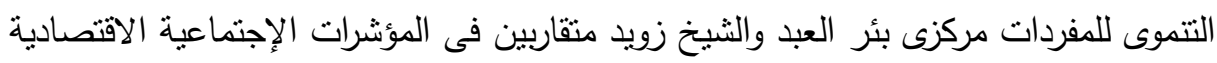

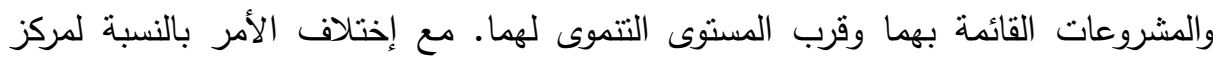
الحسنة والذى يعد المركز الأقل تتمية. ودراسة (تهامى، ^ . . ץ) استهدفت الدراسة التعرف علي درجة فعالية تتمية موارد مطروح وذلك من خلال التعرف علي مدي قدرة المشروع علي تعبئة الموارد اللازمة لتتفيذ الأنشطة وتوظيف الموارد المتاحة من خلال العمليات التنظيمية لتنفيذ الأنشطة وعلي إثباع المتطلبات 
التتموية للمستقيدين، وعلاقتها بالمتغيرات المدروسة - التعرف علي أهم معوقات المشروع وذلك من وجهتي نظر الجهاز الفني والمستقيدين من المشروع، وكذا مقترحاتهم للتغلب عليهاالتعرف علي أهم الآثار الإجتماعية والبيئية المترتبة علي تتفيذ أنشطة المرحلة الأول. أوضحت النتائج أن نسبة المبحوثين الذين يرون قدرة المشروع علي تعبئة الموارد بدرجة الدئه

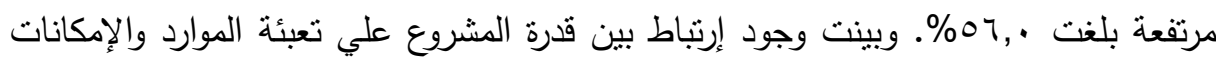
اللازمة لتنفيذ الأنشطة من جهة وبعض المتغيرات الثخصية والنتظيمية للجهاز الفني بالمشروع من جهة أخري. وأتضح أن حوالي ا,_^\% من إجمالي المبحوثين يرون إنخفاض

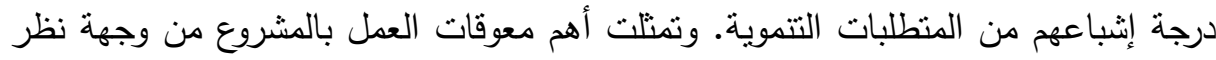

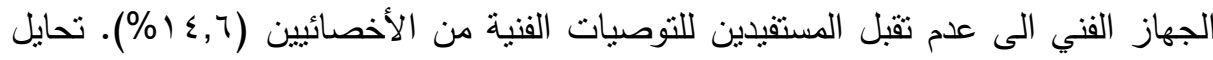

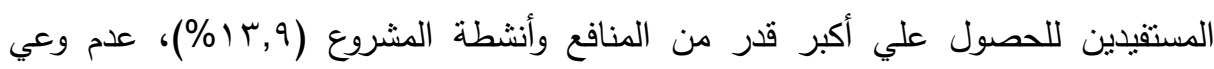

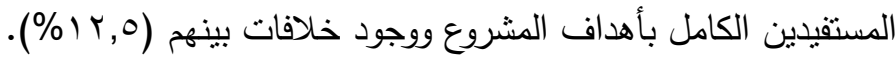

ودراسة (سليم، 1 • ( ) استهدفت الدراسة التعرف على الخصائص والسمات المختلفة داخل بنية مجتمع شمال سيناء، وإلقاء الضوء على الأثر الذى تلعبه تلك التغيرات فى إقامة نمط معين من الحياة الإجتماعية ودراسة التغيرات البيئية والثقافية التى طرأت على البنية الإجتماعية فى مجتمع شمال سيناء. واظهرت النتائج حدوث تغيرات بيئية وثقافية فى مجتمع شمال سيناء منل إنتشار الثقافة الحديثة والقنوات الفضائية والوعى السياسي وكان لها تأثير على البيئة الإجتماعية، وإدراك أبناء مجتمع شمال سيناء أن عناصر نقافتهم المحلية فى خطر ولئه مما دعاهم لمزيد من التمسك بعاداتهم وتقاليدهم الإيمانية مما أثز على البنية الإجتماعية فى الإهى

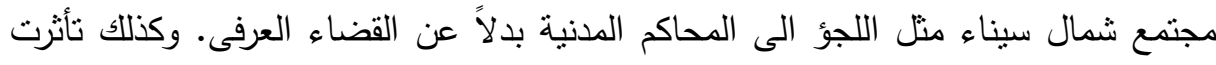

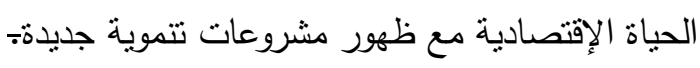

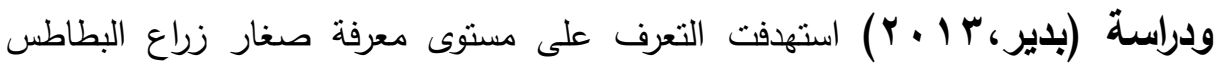
لشروط تصديرها لدول الإتحاد الأوروبى، وتحديد الآثار الإجتماعية والبيئية والمشكلات التى مئى

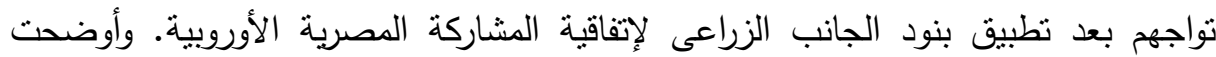

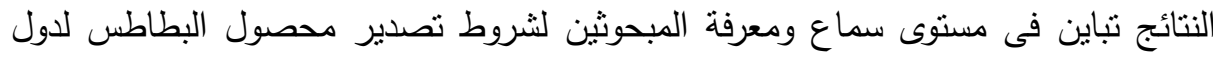


الإتحاد الأوروبى. كما أظهرت زيادة فى حجم الآثار الإجتماعية والآثار البيئية الإيجابية على

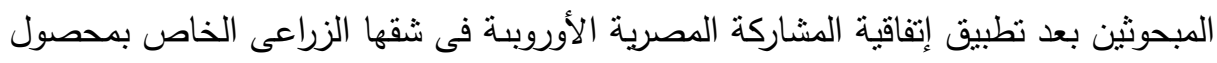

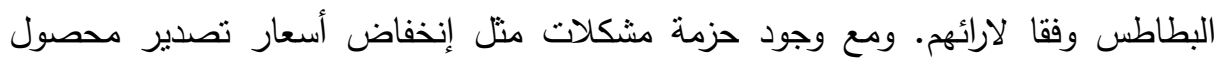
البطاطس، ضألة فرص تسويقه محليا، عدم مصداقية الثركات فى التعاقد على التقاوى وعدم وجود منافذ لنسويق المحصول محلياً، إنخفاض اسعار بيعه محلياً، تدهور شبكة الصرف الزراعى.

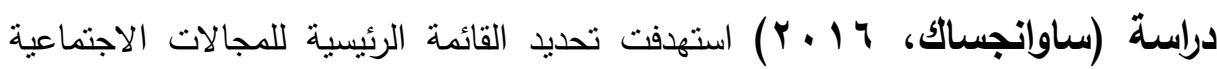

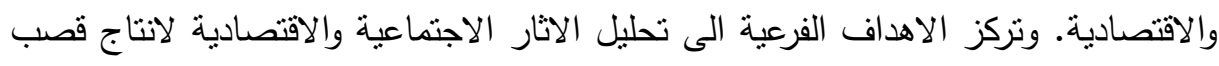

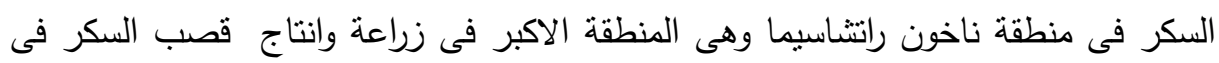

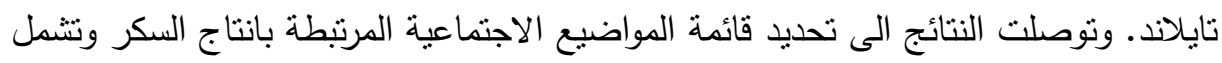

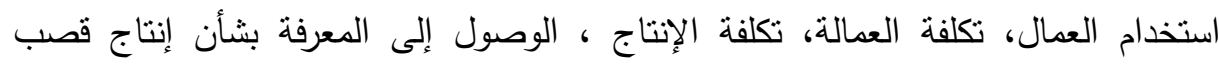

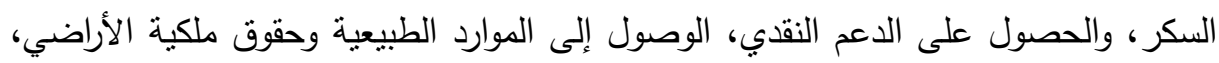

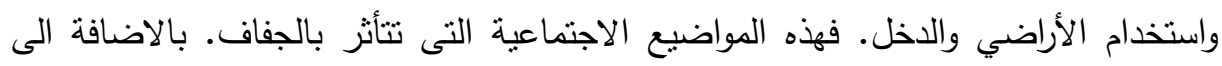

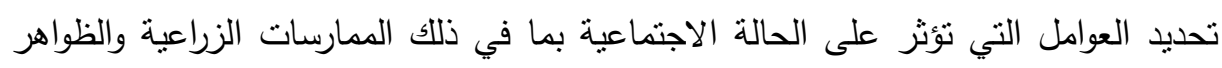
الطبيعية وآلية مصنع السكر (العقد الزراعة). وكذلك تحديد بعض العوامل الاجنماعية المنوافقة

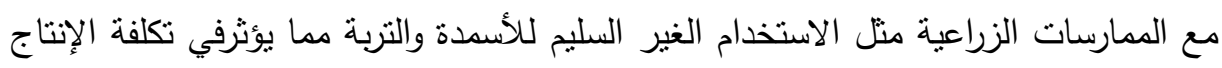

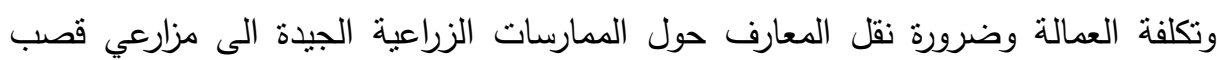
السكر مثل استخدام فائض الأسمدة ومحسنات التربة ومبيدات الآفات لزيادة العائد وتقليل تكلفة

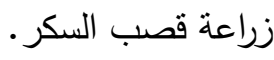
ودراسة (اوكونين، 17 • ب استهدفت الوصول الى فهم عميق لمشاريع الطاقة المتجدة

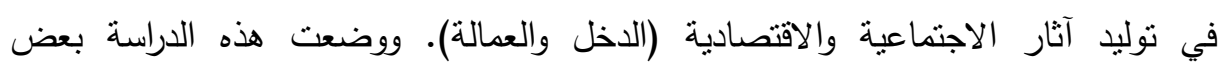
الافتراضات كضرورة وجود الملكية والسيطرة داخل المجتمع من اجل تأمين الآثار ، مثل الآثار

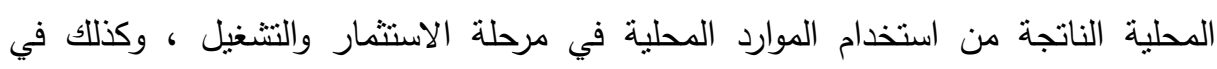
القرارات المتعلقة بإعادة استثمار العائدات. 
أظهرت النتائج أن مرحلة البناء تؤدى الى زيادة في الاقتصاد الإقليمي بنحو ^, ا مليون

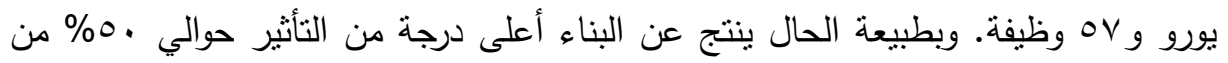

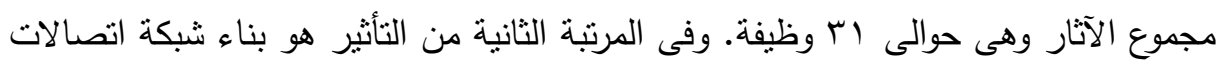

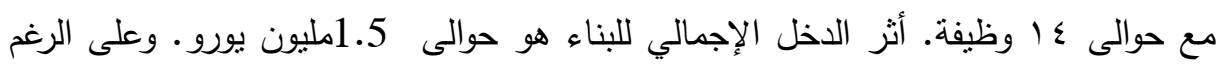
من أن الآثار الاقتصادية والاجتماعية تبدو ملحوظة، فان هذه الوظائف تتواجد فقط أثناء

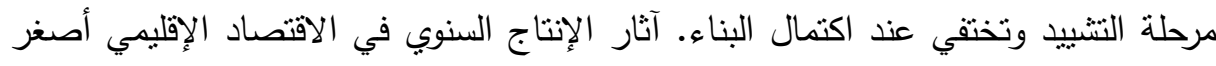

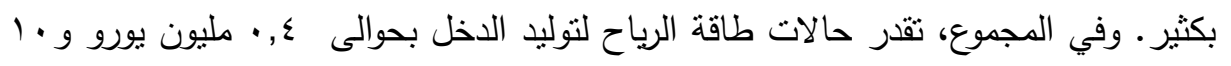

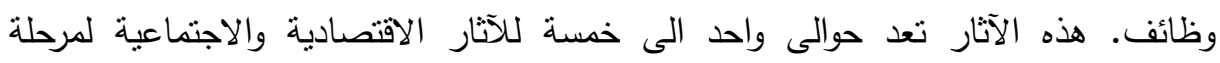

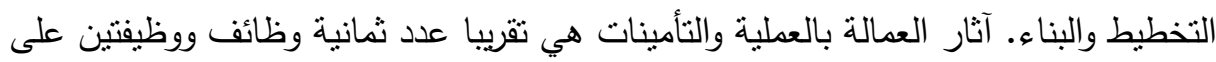

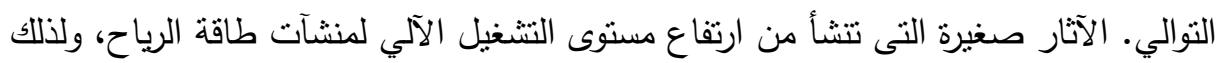

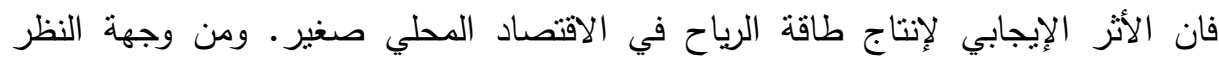

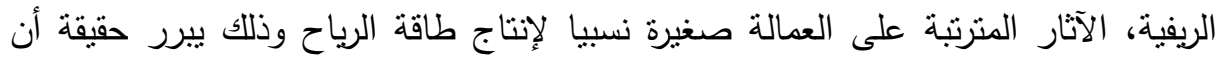

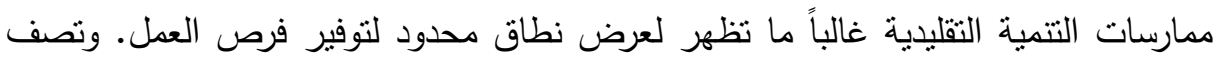

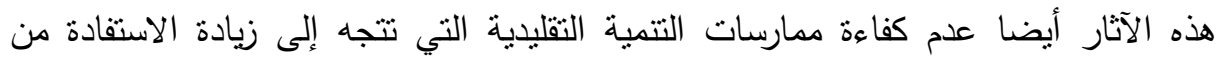
الموارد النقية في المناطق الريفية دون أية محاولات لزيادة القيمة المضافة للموارد الطبيعية.

\section{الإجباءائ المنهجية}

1 - المنهج المستخدم: تعد هذه الدراسة من الدراسات الوصفية التحليلية، وكذلك منهج

المسح الاجتماعي بالعينة بالاستعانه بالاسنبيان والوسائل الاخرى المستخدمه مثل المقابلة

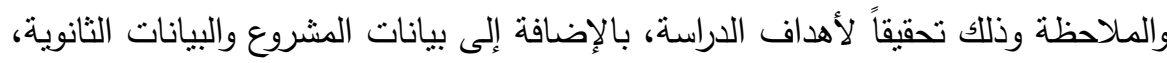
وبعض المصادر المتوفرة على الثبكة الدولية للمعلومات. r - أدوات جمع البيانات :إعتمد البحث على مصدرين للحصول على البيانات: 
أولهما المصادر الثانوية المتمتلة في البيانات والتقارير الخاصة بمشروع تتمية الزراعات الملحية، والإدارة الزراعية بمنطقة سهل الطينة، ومركز المعلومات بمحافظة شمال سيناء وذلك للحصول على البيانات المتعلقة بتحديد عينة البحث. أما ثاني هذه المصادر فيتعلق بالبيانات المحققة لأهداف البحث، والتي جمعت من مصادرها

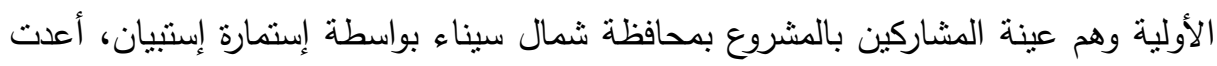
لهذا الغرض بالاضافة الى الملاحظة والمقابلة الثخصية. وتألفت إستمارة الإسنبيان التى إستخدمت في هذا البحث من جزئين رئيسين، أولهما:

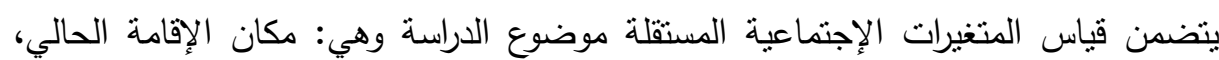

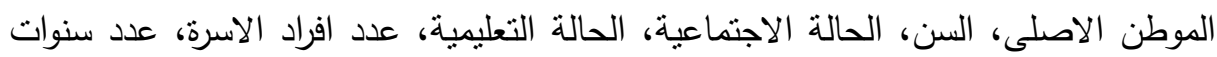

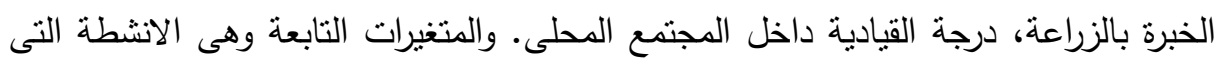

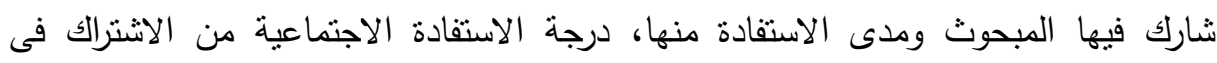

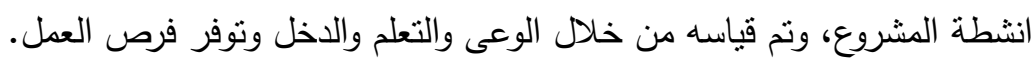

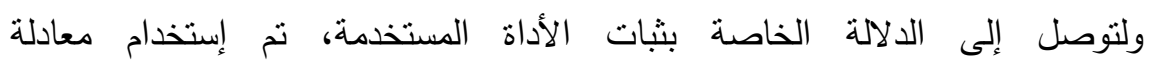

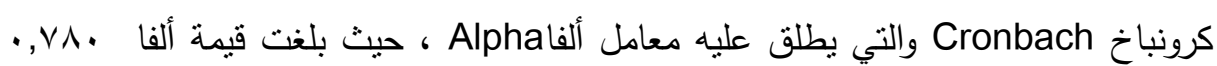
ويعنبر ذلك دليل على ثابتها.

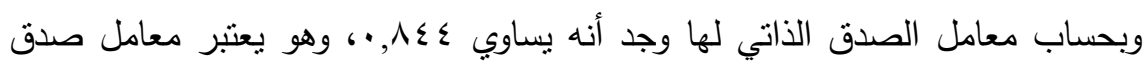

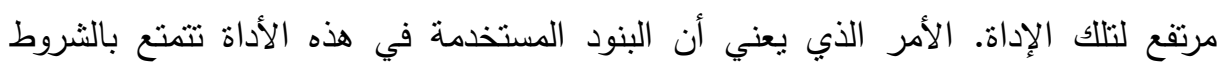
الواجب نوافرها في أداة القياس المناسبة والموثوقة. صدق التحكيم: نم عرض إستمارة الإستبيان الخاصة بتجميع بيانات هذا البحث في صورنه صورتها

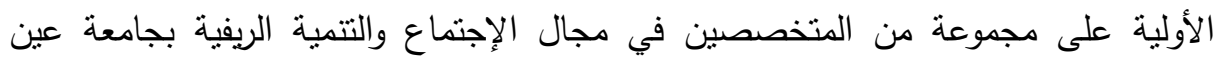

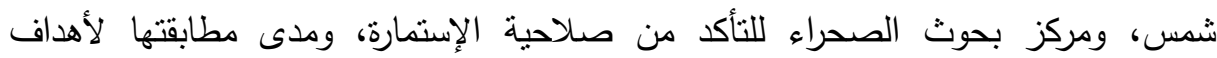
البحث، وتم الحصول على أرائهم في الإستمارة وعناصرها، وبنود المقاييس المستخدمة بها، ونداء

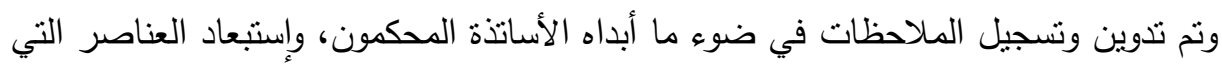


حصلت على أقل من ،^٪ من أرائهم، وبذا أصبحت الإستمارة صالحة لتجميع البيانات الميدانية في صورتها الحالية. r- عينة البحث: لما كان هذا البحث يستهف دراسة الاثر الإجتماعي المرتبط بالاثتراك بمشروع تتمية الزراعات الملحية فى شمال سيناء فإنه يمكن تتاول شاملة البحث من المشتركين بالمشروع على النحو التالى: شاملة البحث: وتتطوي على إجمالي المزارعين

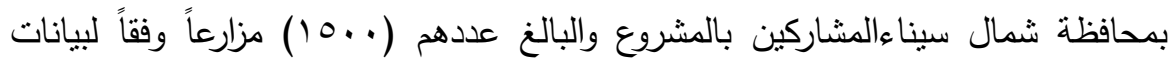
المشروع. وبخصوص عينة البحث من إجمالي المزارعين المشاركين بالمشروع بلغ عددهم

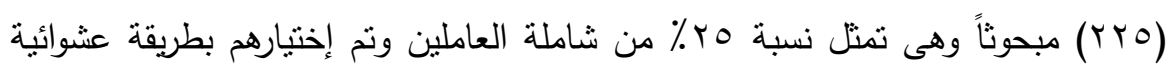

$$
\text { بسيطة من واقع كثوف المشروع. }
$$

وصف عينة الدراسة: نتراوح اعمار \%ov,^\% من إجمالي المزارعين بالمشروع من سن •ـ

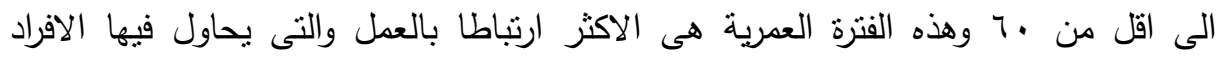
الاستفادة من التطورات الى تحدث بالمجتمع. وهم الاكثر استيعابا وتقتحا لهذه التطورات مقارنة

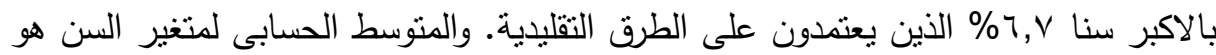

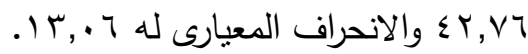

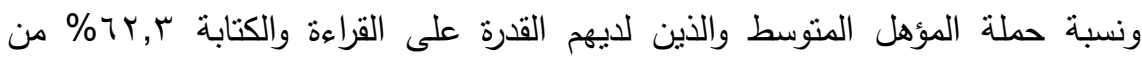
إجمالي نسبة المزارعين بالمشروع وهذا يوضح ان المتعلمين والقادرين على القراءة والكتابة لديهم افق ارحب فى تقبل الطرق المنطورة للزراعة وان نسبة الحاصلين على شهادة عليا ضعيفة جدا r, ا \% و هذ بسبب ان الحاصلين على المؤهلات العليا يفضلون العمل بالمؤهل وليس العمل بالزراعة.

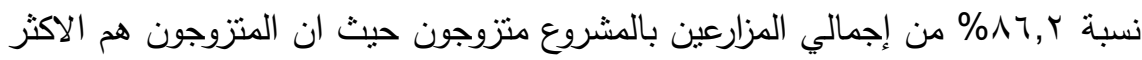

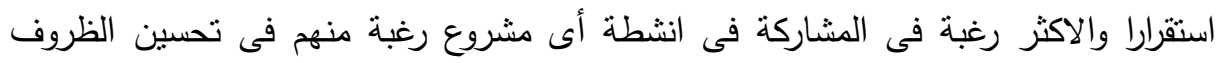

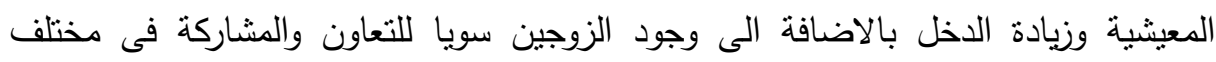
الانشطة كذلك وجود انشطة مناسبة للمراه اكثر من الرجل منل تصنيع الالبان فمشاركتهما سويا تزيد من فرص التعلم والاستفادة. 


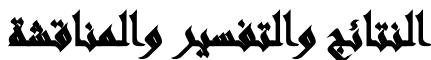

نتائج البحث ومناقشتها: يمكن عرض نتائج البحث على النحو التالي: أولاً النتائج الخاصة بالاستفادة الاجتماعية للمبحوثين بشكل عام

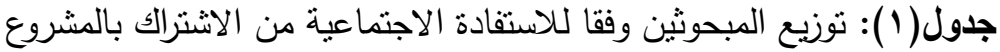

\begin{tabular}{|c|c|c|}
\hline النسبة المئوية \% & 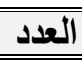 & الاستفادة الاجتماعية من الاشتراك بالمشروع \\
\hline 11,7 & rq & منوسطة: من ^ الى اقل من 17 \\
\hline$\Lambda \wedge, \Sigma$ & 199 & مرتفعة: من T I الى YY \\
\hline$\% 1 \ldots$ & TYO & المجموع \\
\hline
\end{tabular}

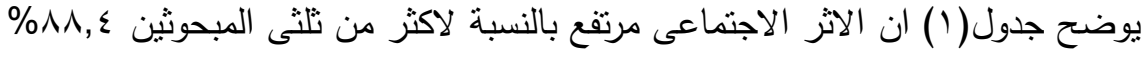

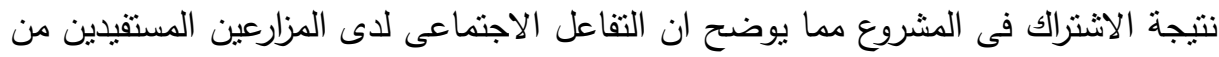
المشروع كان كبيرا وان مجهودات فريق العمل بالمشروع كانت مخططة وموجهة نوجيها سليما. بما تضمنته هذه المجهودات من تقنيات حديثة ومدارس حقلية ودورات تدريبية وارشادية وزيارات حقلية ومتابعة دورية. بالاضافة الى ان هذه النتيجة توضح ان انشطة المشروع المقدمة للمزارعين كانت شاملة وكانت ناتجة من احتباجات فعلية للمزارعين انفسهر مما كان لله

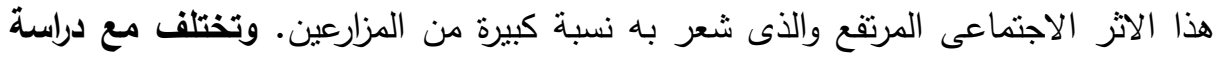

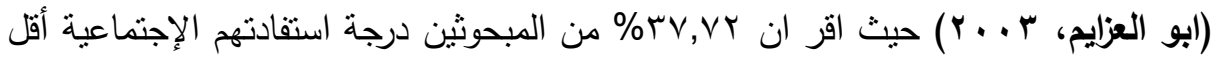
من المتوسط.

تتاولت الدراسة الاثر الاجتماعى الواقع على المشاركين بالمشروع من حيث ثلاث متغيرات وهى الوعى والتعلم والاخل وتوفر فرص العمل. 
ثانياً: النتائج التى توضح الاثر الاجتماعى للمبحوثين من خلال المتغيرات

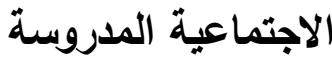

1-النتائج الخاصة بالاثر الاجتماعى المرتبطة بالمتغير الاول وهو الوعى:

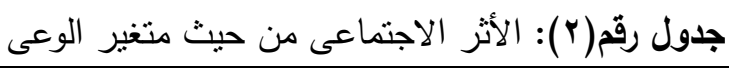

\begin{tabular}{|c|c|c|c|c|c|}
\hline $\begin{array}{c}\text { المتوسط } \\
\text { المرجح } \\
\text { المتح }\end{array}$ & مرتفعة\% & متوسطة\% & منخفضة\% & الاثر الاجتماعى من حيث متغير الوعى & م \\
\hline$\% 9 \cdot, \wedge 9$ & $\wedge \neg, \vee$ & $\Lambda, \varepsilon$ & $\varepsilon, 9$ & مدى زيادة الوعى في النواحى الزراعية & 1 \\
\hline $\begin{array}{c}\Lambda V \cdot \Lambda V \\
\%\end{array}$ & $\vee \wedge, r$ & 19,1 & $r, Y$ & مدى زيادة الوعى باهمية المياه والمحافظة & r \\
\hline$\% \wedge \vee, 0 ૫$ & ᄉr,l & $\wedge, 9$ & $\wedge$ & زيادة الوعى الصحى وتقليل نسبة انتشار & ب \\
\hline$\% \wedge \neg, \neg \vee$ & $\wedge r, 1$ & $\wedge, 9$ & $\wedge, 9$ & مزاملة الجيران وتجمعهم وتعاونهم فى احدهم & $\varepsilon$ \\
\hline & $\wedge T, \vee$ & Ir & $1, r$ & متغير الوعي & \\
\hline
\end{tabular}

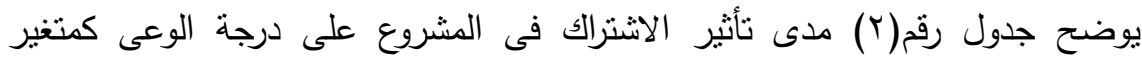

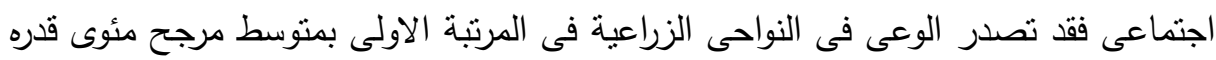

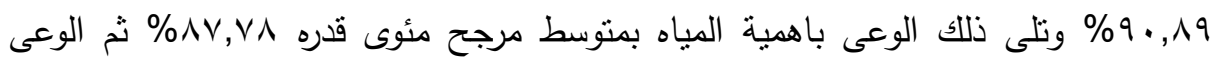

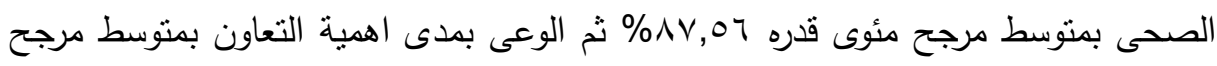

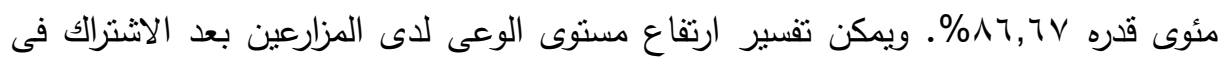

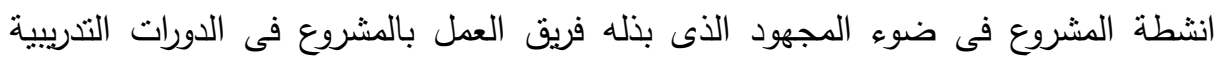

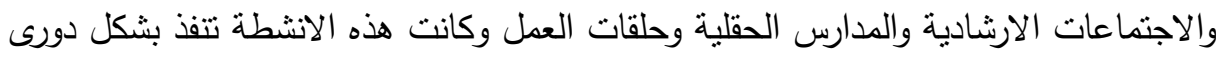

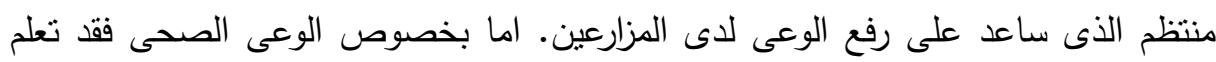

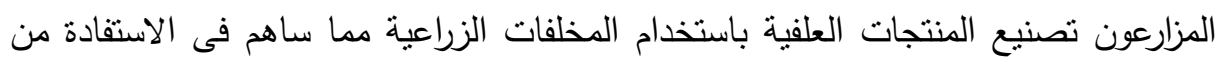

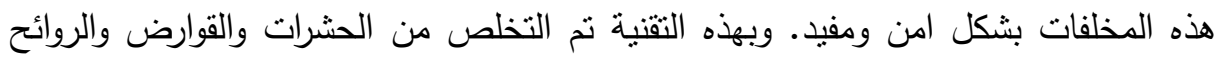

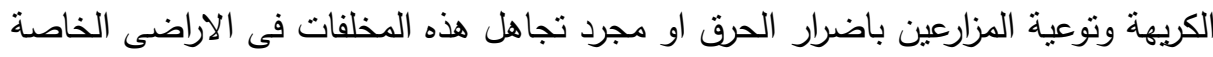

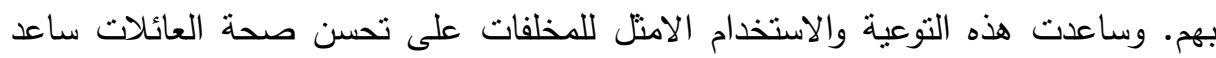
على الخفض من نسبة انتثار الامراض.وقد اتفقت ثلك النتيجة مع (نصار، ، . . ب). 
r-النتائج الخاصة بالاثر الاجتماعى المرتبطة بالمتغير الثانى وهو التعلم: جدول رقم(؟): الاثر الاجتماعى من حيث التعلم

\begin{tabular}{|c|c|c|c|c|c|}
\hline 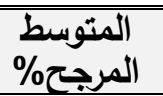 & مرتفعة & متوسطة & منغضة & الاثر الاجتماعى من حيث التعلم & b \\
\hline$\% \wedge \wedge$ & $\Lambda$. & 17 & $\varepsilon$ & تتمية مهارات المرآه فى تصنيع الزئنات & 1 \\
\hline$\% \wedge 0,11$ & $\vee 0,7$ & 19,1 & $0, r$ & زيادة الخبرات في نظم الادارة & r \\
\hline$\% \wedge \varepsilon, 7 \vee$ & $\vee 9,7$ & $1 \cdot, r$ & $1 \cdot, \cdot$ & مدى تطوير قدراتك في مجالات الزراعية & r \\
\hline \multirow[t]{2}{*}{$\% \wedge r, 1)$} & $\vee 0,0$ & 10,1 & $9, r$ & اكتساب مهارات جديدة في الانتاج & $\varepsilon$ \\
\hline & $\Lambda Y, Y$ & 10,1 & $\overline{r, V}$ & متغير التعلم & \\
\hline
\end{tabular}

يوضح جدول رقم (r) مدى تأثثر الاشتراك فى المشروع على درجة التعلم كمتغير

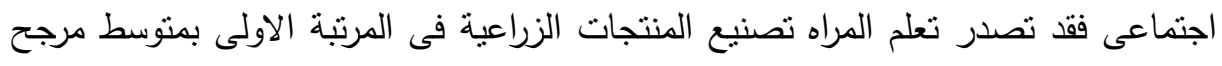

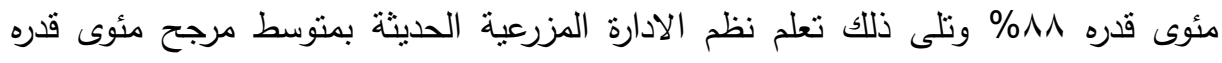

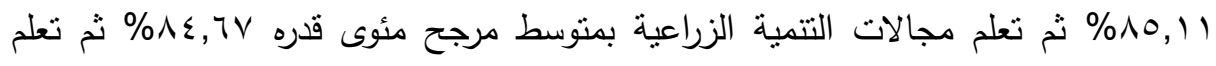

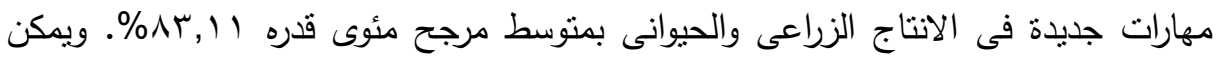

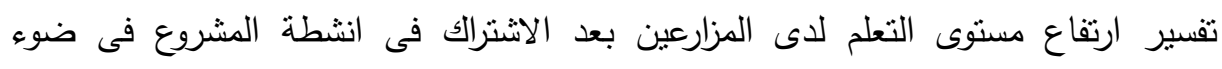

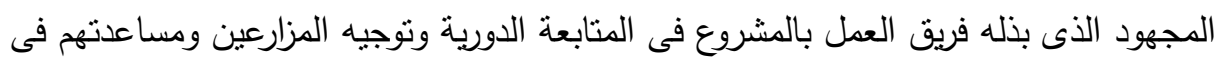

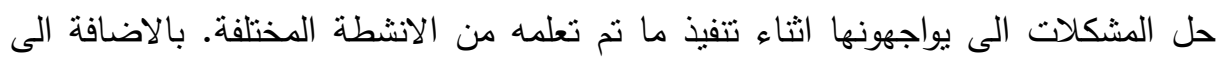

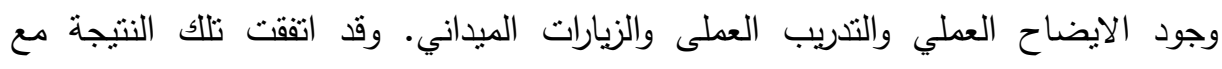

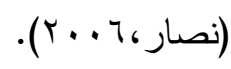


r-النتائج الخاصة بالاثر الاجتماعى المرتبطة بالمتغير الثالث وهو الاخل وتوفر فرص

جدول رقم(ع): الأثر الاجتماعى من حيث الاخل وتوفر فرص العمل الاجل

\begin{tabular}{|c|c|c|c|c|c|}
\hline المتوسط\% & مرتفعة & متوسطة & منغضة & الاثر الاجتماعى من العملث الاخل وتوفز & P \\
\hline$\% 9 \leqslant, 11$ & $\wedge \wedge, \varepsilon$ & 11,7 & - & للاسرى والقتشية وتقليل البطالة بالنسبة & 1 \\
\hline$\% \wedge 9,11$ & $\Lambda \Gamma, T$ & 11,1 & $0, r$ & زيادة مشاركة المرأه والاستفادة من دخلها & $Y$ \\
\hline$\% \wedge \vee, r \mu$ & $\Lambda, r$ & ir & $7, \mathrm{~V}$ & زآرتفادة مشاركة الفراد الاسرة فى العمل & r \\
\hline & $\Lambda Y, V$ & $T V, r$ & . & متغير الدخل وتوفر فرص العمل & \\
\hline
\end{tabular}

يوضح جدول رقم (ء) مدى نأثير الاشتراك فى المشروع على توفر فرص العمل ارتفاع

الدخل كمتغير اجتماعى فقد تصدر التشغيل وتقليل البطالة بالنسبة للسرة والقرية فى المرنبة الاولى بمنوسط مرجح مئوى قدره r r, 9\% وتلى ذللك زيادة مشاركوة المرأه والاستفادة من

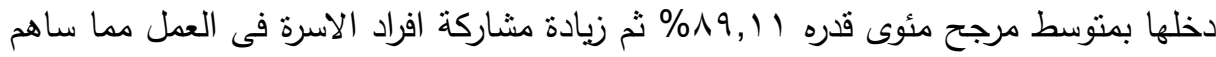

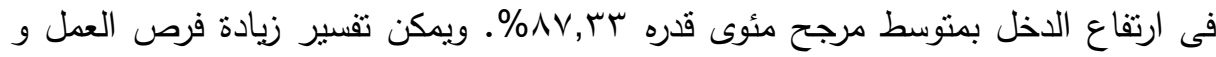
التتغيل وارتفاع الدخل لاى المزارعين بعد الاشتراك فى انشطة المشروع فى ضوء المجهود

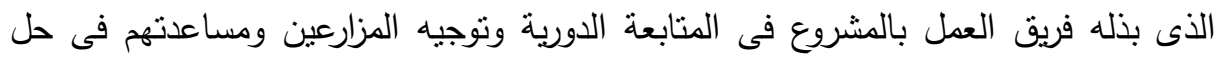
المشكلات الى يواجهونها اثثاء تتفيذ ما تم تعلمه من الانشطة المختلفة. بالاضافة الى وجود الايضاح العملي والتدريب العملى والزيارات الميداني. حيث قام المشروع بتعليم المبحوثين

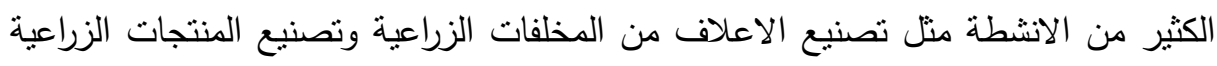

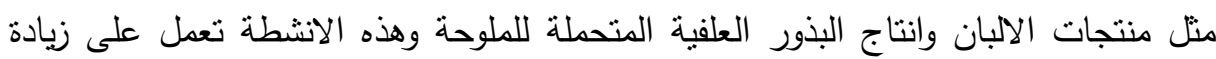
فرص العمل بجانب الاعمال المزرعية وتساهم فى تحسين الدخل سواء عن طريق بيع المنتجات او الاستخدام المنزلى حيث توفر جزء من المبالغ النى ينم صرفها. وونتفق هذه ونه

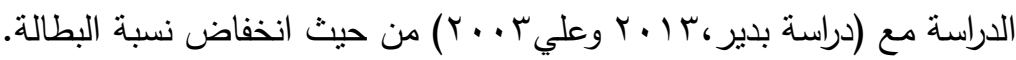




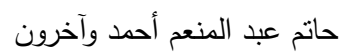

ع - النتائج الخاصة بعلاقة الارتباط بين الاستفادة الاجتماعية مع متغيرات الدراسة

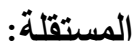

جدول رقم(ه): علاقة الاستفادة الاجتماعية من الاشتراك بالمشروع مع متغيرات الدراسة

\begin{tabular}{|c|c|c|c|}
\hline 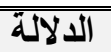 & الارتباط & المتضيرات & 5 \\
\hline., .0 & $*, \Gamma \cdot \tau$ & السن & 1 \\
\hline$\cdot, .0$ & *, YYT & الحالة الاجنماعية & r \\
\hline$\cdot, \cdot 1$ & $* *, \vee \cdot 0$ & الحالة التعليمية & r \\
\hline., .0 & $* \cdot, Y 19$ & عدد افراد الاسرة & $\varepsilon$ \\
\hline$\cdot, \cdot 0$ & $* \cdot, \varepsilon \mid \mathrm{V}$ & مساحة الارض الزراعية & 0 \\
\hline$\cdot, \mu \cdot \Lambda$ & $\cdot, \cdot 7 \wedge-$ & عدد سنوات الخبرة بالزراعة في منطقة شمال سيناء & 7 \\
\hline$\cdot, .0$ & $*,\{\vee \uparrow$ & المهارة القيادية & $\mathrm{v}$ \\
\hline
\end{tabular}

اتضح من الجدول رقم (0) انه لا نوجد علاقة ارتباط بين عدد سنوات الخبرة بالزراعة

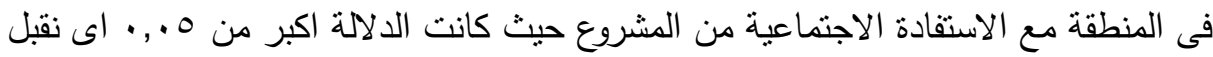
الفرض الصفرى وهو عدم وجود علاقة بينهما.

وتوجد علاقة ارتباطية معنوية موجبة عند المستوى الاحتمالى 0 ., • بين متغير الاستفادة الاجتماعية من المشروع وبين كلا من (متغير السن والحالة الاجتماعية وعدد افراد الاسرة الإنه ومساحة الارض الزراعية والمهارة القيادية).

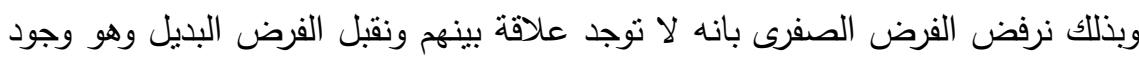

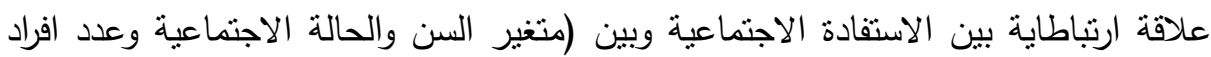
الاسرة ومساحة الارض الزراعية والمهارة القيادية).

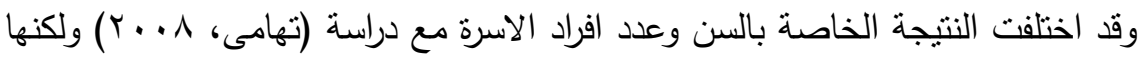
اتفقت معه فى وجود علاقة بين الاستفادة الاجتماعية مع متغير مساحة الارض الزراعية

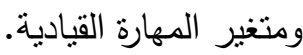

وتوجد علاقة ارتباطية معنوية موجبة عند المستوى الاحتمالى ا +,. بين متغير الاستفادة الاجتماعية من المشروع وبين الحالة التعليمية وقد يرجع ذلك الى ان مستوى التعليم يساعد

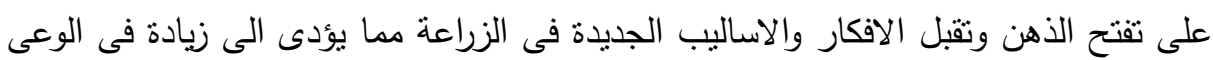
والتعلم والصحة. وبذلك نرفض الفرض الصفرى بانه لا نوجد علاقة بينهم ونقبل الفرض البديل 
وهو وجود علاقة ارتباطاية بين الاستفادة الاجتماعية وبين الحالة التعليمية بمستوى قوى.

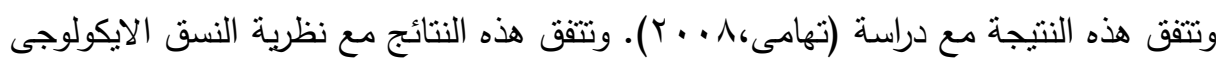

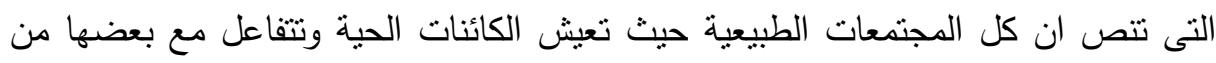

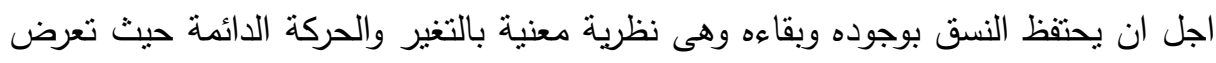

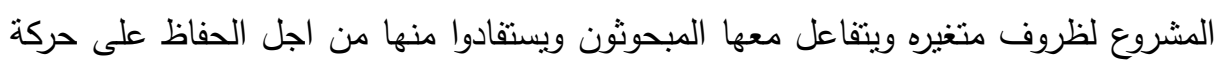
النسق وعلى بقاء المشروع وكذللك الاهتمام باراء المستفيدين من المشروع كعملية تغذية مرتدة

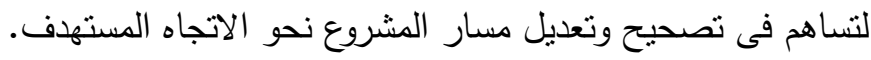

\section{اللزوصيامت}

في ضوء النتائج التي أسفرت عنها الدراسة، وفي ضوء المناقشة السابقة لهذه النتائج

يمكن استخلاص بعض التوصيات التي قد تقيد في تفعيل تحقيق أهداف المشروع في المراحل التالية وتفيذ كذللك فى وضع استراتيجية لمشروعات التتمية بوجه عام والزراعات الملحية بشكل

ا-ضرورة انثاء جمعية تعاونية زراعية بكل منطقة تضم صغار المزارعين. r-زيادة عدد المشروعات التتموية الزراعية وخاصة التى تعتمد على الزراعات الملحية بسبب طبيعة المنطقة واحتباجها لمثل هذا النوع من الزراعات. r-مساعدة المزارعين فى عمليات التسويق للمنتجات المصنعة. ع-نطوير عمليات الرى بالاساليب الحديثة لقلة توفير الكهرباء.

ه- عمل دورات تدريبية خاصة بالتغيرات المناخية واثارها وكيفية مواجهتها. 7-زيادة اعداد الافراد الذين يتم ضمهم للمشروع وخاصة البدو . V- استحداث سلالات حيوانات جديدة. 


\section{zall}

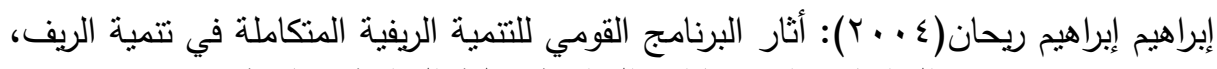

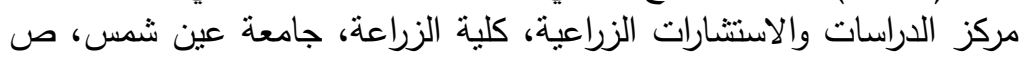

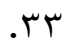

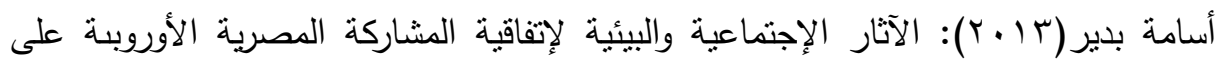

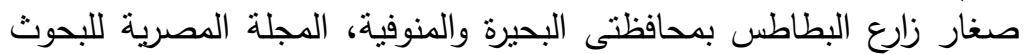

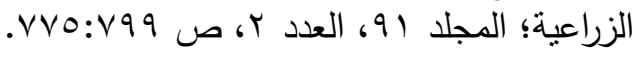

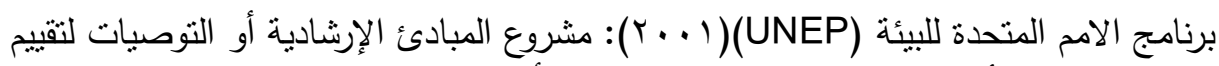

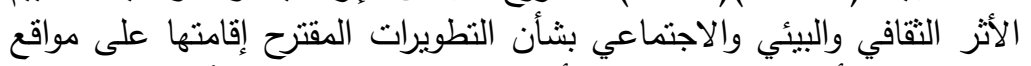

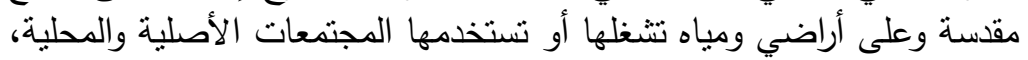

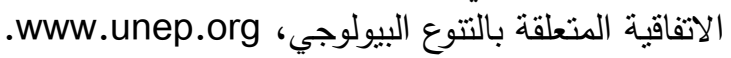

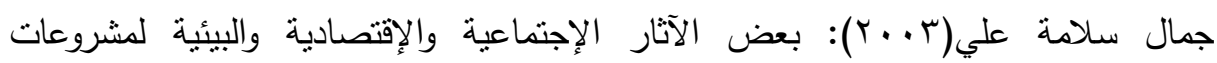

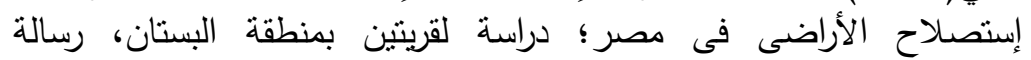
ماجستير ، كلية الزراعة، جامعة القاهرة.

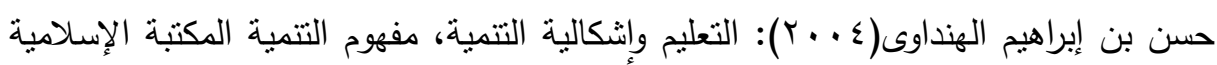

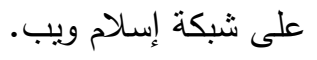

حسين حجازى: التحديات التى تواجه الزراعة المصرية وكيفية مواجهتها، مصر ، وجلة إبلة الأهرام

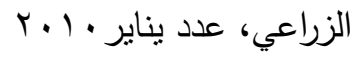

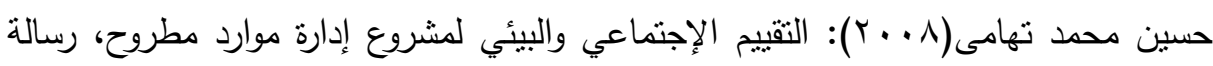
دكتوراه، كلية الزراعة، جامعة القاهرة.

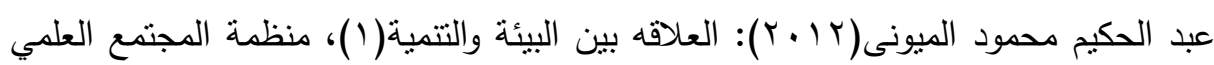

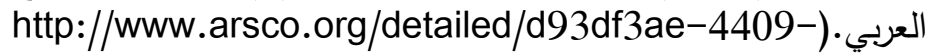
45d0-a922-eedaa981ea46

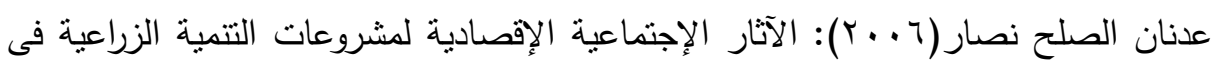

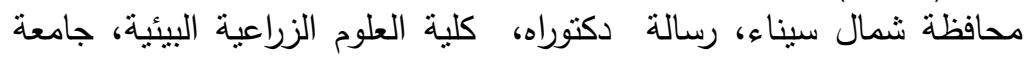

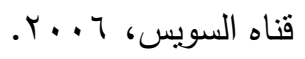

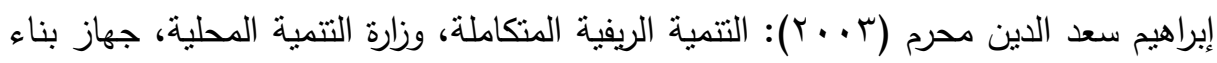

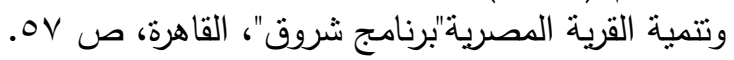




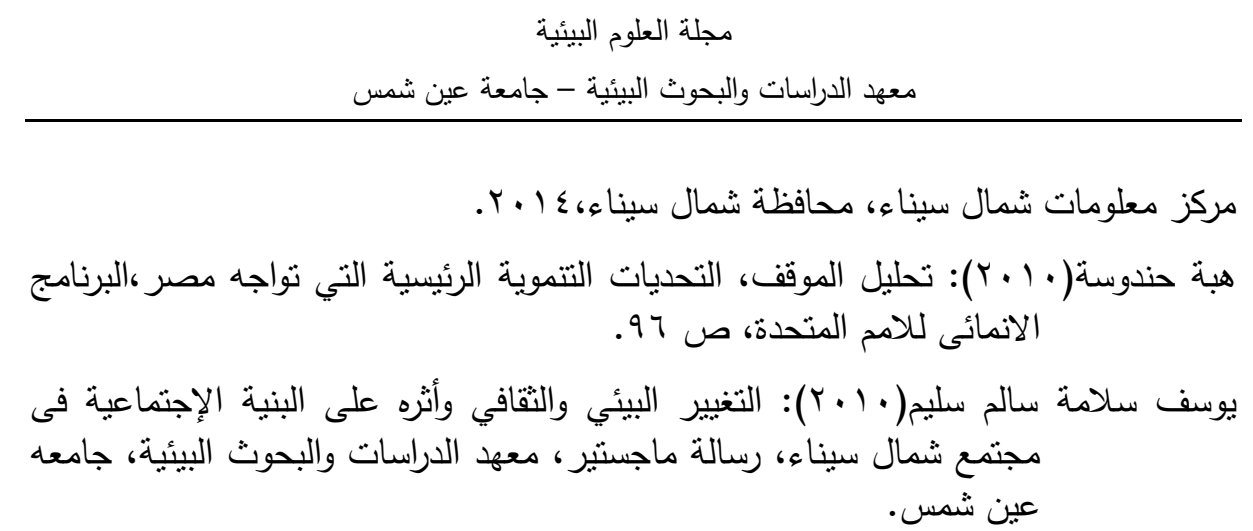

Freeman, A.M.; Haveman, R.H. and Kneese A.V. (1973): The Economics of Environmental Policy, John Wiley, New York, London, p.19.

Grignon; Claude, Abdelly; Chedly, Öztürk; Münir and Ashraf; Muhammad(2008):Biosaline Agriculture and High Salinity Tolerance, El-Shaer; Hassan M. \& El-Morsy; Mohamed H., "Potentiality of salt marshes in Mediterranean coastal zone of Egypt", Springer Science \& Business Media, New York,P.P.207,220.

Okkonen, Lasse; Lehtonen, Olli (2016): Socio-economic impacts of community wind power projects in Northern Scotland, Renewable Energy journal, Vol.85, pp. 826-833.

Porto, E. R.; Amorim, M. C.; Dutra, M.T.; Paulino, R. V.; Brito, T. L.; and Matos, A.N. (2006): Rendimento da atriplex nummularia irrigada com efluentes da criação de tilápia em rejeito da dessalinização de água, Revista Brasileira de Engenharia Agrícola e Ambiental, 10(1), pp. 97-103.

Qureshi, R.H.; Lennard, E.G. (1998): Saline Agriculture for Irrigated Land in Pakistan: A Handbook, Australian Centre for International Agricultural Research Canberra, Australia, p.2.

Rabel, J.Burdge (1999): A Community Guide to Social Impact Assessment, Middleton, Social Ecology Press, USA, p.160.

Sawaengsak, Wanchat; Gheewala, S.H.(2016): Analysis of social and socio-economic impacts of sugarcane production: a case 


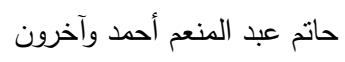

study in Nakhon Ratchasima province of Thailand, Journal of Cleaner Production.(in press).

World Bank (1991): World Development Report, The Challenge of Development, New York, Oxford University Press.

Yensen, N. P.(2006): Halophyte Uses for the Twenty-First Century, in Ecophysiology of High Salinity Tolerant Plants, Springer, Berlin, Germany, pp. 367-396.

\title{
SOCIAL IMPACT OF SALINE AGRICULTURE \\ DEVELOPMENT PROJECT ON SMALLHOLDER \\ FARMERS IN NORTH SINAI GOVERNORATE
}

\author{
Abdelmoneim, H. A. ${ }^{(1)}$; Elkassas, H. I. ${ }^{(1)}$; \\ Mohamed, Ashoura, H. ${ }^{(2)}$ and Rakha, Arig, M. ${ }^{(2)}$ \\ 1) Institute of Environmental Studies and Research, Ain Shams \\ University. 2) Desert Research Center
}

\begin{abstract}
ABSRACT
The present study aims to identify the social impact of saline agriculture projects on small farmers in terms of awareness, education, increase job opportunities and higher incomes. It also aims to have specific recommendations for the optimization of saline agriculture project. It aims to be aware of the most important problems facing the expansion of such crops to benefit from them in the future. Thus, the importance of this study lies in its attempt to study the new social effects on farmers who participated in the project, in addition to, the importance of saline agriculture in maintaining the environment and help small farmers in improving their income. The implementation of the project in North Sinai Governorate increases the importance of the study regarding the importance of Sinai for national security.
\end{abstract}

$$
\text { المجلد السادس والثلاثون، الجزء الثالث، ديسمبر } 17 \text { ـ ب }
$$


A sample of 225 farmers was selected. They have benefited from the project either directly through the participation in activities, or indirectly by learning from neighbors. Basic information has been collected from the data of the project. The respondents have been interviewed using a questionnaire.

The study has a number of results such as; there is a rise in farmers' awareness and knowlge of modern methods of farming. They have understood the modern methods of agriculture and began to practice them especially in saline agriculture methods. There is an improvement in the health of farmers and their families. As well as the development of women's skills in the processing of agricultural products (both feed products and dairy).

The research had some recommendations such as establishing an agricultural cooperative association for small farmers, increasing the number of agricultural development projects, particularly saline agriculture, helping farmers in marketing the manufactured products, and the development of irrigation systems. 